\title{
Biologically Active Constituents of Soybean
}

\author{
Tzi Bun Ng, Randy Chi Fai Cheung and \\ Jack Ho Wong
}

Additional information is available at the end of the chapter

http://dx.doi.org/10.5772/52526

\section{Introduction}

A diversity of bioactive biomolecules present in soybean is covered in this chapter such as e-Phe-Leu and Trp-Leu, and Val-Leu-Ile-Val-Pro derived from glycinin; Bowman-Birk inhibitor, Kunitz trypsin inhibitor, hemagglutinin, isoflavone-deprived soy peptide, neutral PR-5 protein, SbPRP protein, ferritin, peroxisomal proteins, defense proteins such as calmodulin, disease resistance protein, beta-glucan-binding protein, 1 unasin, and glysojanin; enzymes such as phenylalanine ammonia-lyase and tyrosine ammonia-lyase, defense-related enzymes, cysteine proteinase, isoflavone synthase, isocitrate lyase, vestitone reductase and chalcone reductase, UDP-glucose: flavonoid 3-O-glucosyltransferase, betaglucosidase, isoflavone conjugate-hydrolyzing beta-glucosidase, genes related to 2-oxoglutarate-dependent dioxygenases, 5'-adenylylsulfate reductase, and ATP sulfurylase, anticarcinogenic daidzein-rich fraction, polysaccharides, glyceollins, and isoflavones. The aforementioned soybean constituents manifest many uses and consumption of soybean promotes health.

Soybean represents a rich and yet relatively inexpensive source of proteins. Hence it is a common dietary component in many countries. It is well known that some of its constituents like isoflavones are beneficial to health, and regular consumption of soybean has been associated with a reduced incidence of diseases such as osteoporosis, cancer and cardiovascular disease. A wealth of information pertaining to the various bioactive constituents of soybean has been accumulated. The aim of this article is to review the information that is available. 


\section{Storage proteins}

A combined proteomic approach was employed for the separation, identification, and comparison of two major storage proteins, beta-conglycinin and glycinin, from cultivated (Glycine max) and wild (Glycine soja) soybean seeds. Two-dimensional polyacrylamide gel electrophoresis with three different immobilized $\mathrm{pH}$ gradient strips effectively resolved many storage proteins. The $\mathrm{pH}$ range 3.0 - 10.0 was good for separating most of the beta-conglycinin subunits while $\mathrm{pH}$ ranges $4.0-7.0$ and $6.0-11.0$ were satisfactory for separating acidic and basic glycinin polypeptides, respectively. Although the distribution pattern of the protein spots was in general alike in both genotypes by employing $\mathrm{pH} 3.0$ - 10.0, variations in number and intensity of protein spots were better resolved when a combination of $\mathrm{pH} 4.0-7.0$ and $\mathrm{pH} 6.0$ - 11.0 was utilized. The total number of storage protein spots detected in wild and cultivated genotypes was approximately 44 and 34, respectively [1].

Krishnan et al have developed a fast and simple fractionation technique using $10 \mathrm{mM} \mathrm{Ca}^{2+}$ to precipitate soybean seed storage globulins, glycinin and beta-conglycinin. This method eliminates over $80 \%$ of the highly abundant seed proteins from the extract, facilitating detection of previously inconspicuous proteins in soybean seed [2].

\section{3. $\beta$-conglycinin}

Ferreira et al conducted a study to investigate the effect of daily oral administration of soybean $\beta$-conglycinin (7S protein) (300 $\mathrm{mg} / \mathrm{kg} /$ day) alone and in conjunction with the hypolipidemic drugs fenofibrate $(30 \mathrm{mg} / \mathrm{kg} /$ day $)$ and rosuvastatin $(10 \mathrm{mg} / \mathrm{kg} /$ day $)$ in hypercholesterolemic rats for 28 days. The data reveal that conglycinin exhibits effects similar to those of fenofibrate and rosuvastatin in the control of plasma cholesterol, HDL-C and triglycerides, and suggests that the association of soybean $\beta$-conglycinin with rosuvastatin changes the action of the drug in cholesterol homeostasis [3].

\section{Glycinin}

Glycinin was isolated and characterized from soybeans stored under different ambient conditions (i) in $84 \%$ relative humidity at $30{ }^{\circ} \mathrm{C}$ (adverse conditions) for 9 months and (ii) in $57 \%$ relative humidity at $20^{\circ} \mathrm{C}$, (iii) in the cold $\left(4{ }^{\circ} \mathrm{C}\right.$ ), and (iv) in an uncontrolled ambient garage for 18 months.. Glycinin purified from soybean exposed to the adverse conditions possessed a significant amount of sugar and demonstrated a decrease in hydrophobic interactions after 3 months; the total free sulfhydryl content in glycinin dropped, but the intramolecular disulfide bonds increased; the alpha-helix content of secondary structure underwent a slight rise, but the beta-sheet content fell. The structure of glycinin purified from and subjected to the other three aforementioned conditions remained unaltered after 18 months of storage when 
compared to the control. The molecular mass of glycinin remained in the range of 313-340 $\mathrm{kDa}$ throughout the storage period for all four conditions [4].

Addition of $1 \%$ cholesterol and $0.5 \%$ cholic acid induced hypercholesterolemia in Male Wistar rats without altering weight gain. Daily administration $(300 \mathrm{mg} / \mathrm{kg} /$ day) of glycinin (11S globulin) for 28 days led to a $2.8 \%$ increase of dietary protein intake and resulted in elevated HDL-C, reduced hepatic triglycerides and improved atherogenic index in hypercholesterolemic animals [5].

Sitohy et al [6] isolated glycinin, basic subunit and $\beta$-conglycinin from soybean protein isolate and tested them for antimicrobial activity against pathogenic and spoilage bacteria as compared to penicillin. All three of them demonstrated antibacterial activity identical to or higher than penicillin in the order; basic subunit $>$ glycinin $>\beta$-conglycinin with minimal inhibitory concentration (MIC) of 50, 100 and $1000 \mu \mathrm{g} / \mathrm{ml}$, respectively. The half maximal inhibitory concentration $\left(\mathrm{IC}_{50}\right)$ values of the basic subunit, glycinin and $\beta$-conglycinin were 15 , 16 and $695 \mu \mathrm{g} / \mathrm{ml}$ against Listeria monocytogenes; 17, 20, and $612 \mu \mathrm{g} / \mathrm{ml}$ against Bacillus subtilis; and 18, 21 and $526 \mu \mathrm{g} / \mathrm{ml}$ against S. enteritidis, respectively. Transmission electron microscopy images of L. monocytogenes and S. enteritidis revealed larger sizes and separation of cell wall from cell membrane following treatment with glycinin or basic subunit. Scanning electron microscopy of $B$. subtilis disclosed an irregular wrinkled external surface, fragmentation, adhesion and aggregation of damaged cells or cellular debris following treatment with glycinin or the basic subunits but not with penicillin. All tested substances, especially the basic subunit, manifested enhanced concentration-dependent cell permeation as indicated by crystal violet uptake. Glycinin and basic subunit demonstrated a more rapid antimicrobial action compared with penicillin. The cell killing efficiency was in the following descending order; basic subunit $>$ glycinin $>$ penicillin $>\beta$-conglycinin and the susceptibility of the bacteria to the antimicrobial agents was in the order: L. monocytogenes $>B$. subtilis $>$ S. enteritidis. Addition of glycinin and the basic subunit to pasteurized milk inoculated with the three bacteria; L. monocytogenes, B. subtilis and S. enteritidis (approximately $5 \log \mathrm{CFU} / \mathrm{ml}$ ) impeded their proliferation after storage at $4{ }^{\circ} \mathrm{C}$ for $16-20$ days [6].

\section{Soybean 7S globulin}

In rats fed a hypercholesterolemic diet soybean $7 \mathrm{~S}$ globulin reduced plasma cholesterol and triglycerides and upregulated liver beta- very-low-density lipoprotein (VLDL) receptors [7].

\section{Basic 7S globulin (Bg7S)}

Basic 7S globulin (Bg7S) is expressed by soybeans in response to biotic or abiotic stress. It is capable of binding to a 4-kDa protein involved in cell proliferation. Bg7S is detected in legumes, and other plants. However, its function has not been elucidated. Bg7S has been successfully crystallized. Orthorhombic and monoclinic crystals were procured under various 
conditions and belonged to space groups P2(1)2(1)2, with unit-cell parameters $\mathrm{a}=111.9, \mathrm{~b}=$ $130.1, \mathrm{c}=287.8 \AA$, and P2(1), with unit-cell parameters $\mathrm{a}=85.3, \mathrm{~b}=137.6, \mathrm{c}=162.1 \AA, \beta=$ $91.2^{\circ}$, respectively [8].

\section{Soybean food allergens}

As part of the safety assessment of genetically modified (GM) soybean, 2-dimensional gel electrophoresis analyses were performed with the isoxaflutole and glyphosate-tolerant soybean FG72, its non-GM near-isogenic counterpart (Jack) and three commercial non-GM soybean lines. Rouquié et al [9] compared the known endogenous human food allergens in the seeds of the five different soybean lines to assess any potential unanticipated consequences of the genetic modification. Thirty-seven protein spots representing five well known soybean food allergen groups were quantified in each genotype. Among the various protein spots, the levels of accumulation of three allergens were slightly attenuated in GM soybean than in non-GM counterparts although all allergenic proteins were detected in the different genetic backgrounds. There was no significant rise in the level of allergens in FG72 soybean seeds which can thus be considered as safe as its non-GM counterpart [9].

\section{Immunodominant soybeanallergen P34}

Protein P34 (Gly m Bd 30K) is the immunodominant allergen in soybean. Among commercial soy ingredients, soy flour displayed the highest P34 antigenicity (32 mg/g extracted protein) followed by soy protein isolate $(29 \mathrm{mg} / \mathrm{g}$ extracted protein) and soy protein concentrate $(24 \mathrm{mg} / \mathrm{g}$ extracted protein). Among soy consumer products, soymilk exhibited the highest P34 antigenicity (from 7 to $23 \mathrm{mg} / \mathrm{g}$ extracted protein), followed by tempeh $(8 \mathrm{mg} / \mathrm{g}$ extracted protein), soy infant formula $(3.4 \mathrm{mg} / \mathrm{g}$ extracted protein), soy powder ( $2 \mathrm{mg} / \mathrm{g}$ extracted protein), and soy cheese products $(0.50 \mathrm{mg} / \mathrm{g}$ extracted protein). Korean miso, soy sauce, soy chili mix, soy nuts, soy cream cheese, soy meat patty, texturized soy protein, and soy cereal exhibited undetectable P34 antigenicity (detection limit $=0.45 \mathrm{ng}$ ). Selecting soybean varieties low in this allergen, or via processing, potentially can render soybean products less antigenic [10].

The sera from 3 of 9 (33\%) patients with outgrown soybean allergy and 6 of 9 (66\%) patients with soybean allergy were classified as positive. Sodium dodecyl sulfate (SDS)-treated recombinant P34 retained its structure and biological activity. Recombinant P34 is a useful tool for the analysis of antigen-specific response in soybean allergy. A modified form of recombinant P34 for the diagnosis or treatment of soybean allergy using specific immunotherapy techniques may be available in the future [11]. 


\section{GmPep914}

The peptide DHPRGGNY from soybean leaves, at a concentration of $0.25 \mathrm{nM}$, alkalinizes the media of soybean suspension cells, a response associated with defense peptides. Only 5 to $10 \mathrm{~min}$ are needed to achieve a maximal $\mathrm{pH}$ change. The peptide is present at the carboxyterminal end of a 52-amino acid precursor protein (Glyma12g00990) deduced from the soybean genome project. A search of the soybean databank discloses a homolog (Glyma09g36370) that contains a similar peptide, DLPRGGNY. The synthetic peptide exhibits the same activity. The peptides, designated GmPep914 (DHPRGGNY) and GmPep890 (DLPRGGNY), can induce the expression of both Glyma12g00990 (GmPROPEP914) and Glyma09g36370 (GmPROPEP890) in cultured soybean suspension cells within $1 \mathrm{~h}$. Both peptides induced the expression of defense genes such as CYP93A1(a cytochrome P450 gene implicated in phytoalexin synthesis), chitinase b1-1(a chitinase implicated in pathogen defense), and soybean chalcone synthase1 (Gmachs1), and chalcone synthase, implicated in phytoalexin production. Both GmPROPEP914 and GmPROPEP890 were highly expressed in the roots, relative to the aerial portions of the plant. However, treatment of the aerial portion of soybean plants with hormones involved in elicitation of defense responses revealed augmented expression levels of GmPROPEP914 and GmPROPEP890 [12].

\section{Cyclo(his-pro)}

Cyclo(His-Pro),(CHP), a naturally occurring, cyclic dipeptide structurally related to thyrotropin-releasing hormone, was obtained from soybean meal by hydrolysis with flavourzyme and alcalase. When rat insulinoma cells (RINm5F) were exposed to $2 \mathrm{mM}$ streptozotocin (STZ), insulin secretion declined to approximately half. CHP treatment restored the insulinsecreting activity of RINm5F cells to approximately $71 \%$ of that of untreated control cells. CHP significantly protected the cells from STZ -mediated cytotoxicity via reduction of STZinduced nitric oxide production (2.3-fold) and lipid peroxidation (1.9-fold). STZ-induced apoptotic events, including activation of caspase-3, poly(ADP-ribose) polymerase (PARP) cleavage, and DNA fragmentation in RINm5F cells were attenuated by CHP. These results suggest that CHP could be employed as a protective and therapeutic agent against STZmediated cytotoxicity and apoptosis [13].

\section{Immunostimulating glutamine-rich peptide}

An immunostimulating glutamine-rich peptide, isolated from the soybean protein fraction digested with Rhizopus oryzae Peptidase R, was located at or in the vicinity of the glutaminerich region 202 to 222 of the glycinin G4 subunit. The peptide significantly upregulated the number of $\mathrm{CD} 8(+), \mathrm{CD} 11 \mathrm{~b}(+)$, and $\mathrm{CD} 49 \mathrm{~b}(+)$ cells in $\mathrm{C} 3 \mathrm{H} / \mathrm{HeN}$ mouse spleen cell cultures. Two chemically synthesized glutamine-rich peptides (QQQQQQKSHGGR and 
KQGQHQQEEEEE), corresponding to residues 202 to 213 and residues 214 to 225 of the glycinin G4 subunit, elevated the number of interleukin (IL)-12(+)CD11b(+) cells. Peptide 202-213 increased the number of CD49b(+), IL-2(+)CD4(+), and interferon-gamma(+)CD4(+) cells, and stimulated the cytotoxic activity of splenocytes toward K562 human erythroleukemia cells. The data suggest that the glutamine-rich region of the soybean glycinin G4 subunit enhances the cellular immune system in murine splenocyte cultures [14].

\section{Soy protein}

Soy protein mitigates lipotoxicity in the liver and pancreas in various rodent models of obesity. Dietary soy protein can suppress cardiac cholesterol and triglyceride concentrations and reduce cardiacceramide concentration by downregulating the expression of serine palmitoyl transferase, a key enzyme in sphingolipid biosynthesis in the heart of obese rodents, and by reducing lipid accumulation. Thus, soy protein consumption may be a useful dietary therapeutic strategy for l prevention of lipotoxic cardiomyopathy [15].

\section{Soy protein-derived angiotensin I-converting enzyme (ACE)inhibitory hydrolysate}

Cha and Park [16] produced a soy protein-derived ACE inhibitory hydrolysate and characterized its activity, physicochemical, and biochemical properties. The competitive ACE inhibitory activity remained stable after incubation with gastric enzymes for 2 hours

\section{Angiotensin I-converting enzyme inhibitory peptides}

Two non-competitive ACE inhibitors, Ile-Phe-Leu ( $\left.\mathrm{IC}_{50}, 44.8 \mathrm{M}\right)$ and Trp-Leu $\left(\mathrm{IC}_{50}, 29.9 \mathrm{M}\right)$, were isolated from the tofuyo (fermented soybean food) extract. The first sequence is contained in the alpha- and beta-subunits of beta-conglycinin, while the second sequence exists in the B-, B1A- and BX-subunits of soybean glycinin. The inhibitory activity of Trp-Leu was unaffected by the gastrointestinal proteases pepsin, chymotrypsin and trypsin. About 30\% of the activity remained after successive digestion by these proteases [17].

\section{Angiotensin I-converting enzyme inhibitory peptide derived from glycinin}

The pentapeptide Val-Leu-Ile-Val-Pro derived from glycinin has an $\mathrm{IC}_{50}$ of $1.69+/-0.17 \mathrm{M}$ and $\mathrm{a} \mathrm{K}_{\mathrm{i}}$ of $4.5+/-0.25 \times 10^{-6} \mathrm{M}$ for ACE inhibition. This peptide was resistant to digestion by gastrointestinal proteases [18]. 


\section{Bowman-Birk Inhibitor (BBI)}

The low cancer incidence associated with soybean consumption has been related to the presence of Bowman-Birk inhibitor (BBI) and lectin [19]. Two different strategies were used for the extraction of BBI and lectin. The first method entailed extraction of soybean proteins using Tris- $\mathrm{HCl}$ buffer followed by isolation of $\mathrm{BBI}$ and lectin by isoelectric precipitation of other soybean proteins. The second method involved direct extraction of BBI and lectin using an acetate buffer. The effect of previous delipidation on the extraction of BBI and lectin was examined. The possibility of using a high-intensity focalized ultrasonic probe for expediting the extraction was investigated and the extraction time and ultrasound amplitude were optimized. After evaluation of its analytical characteristics (linearity, precision, and recovery), the method was used for quantitating BBI and lectin in different varieties of soybean [19].

\section{Bowman-Birk (BBI) isoinhibitors}

Two major soybean isoinhibitors, IBB1 and IBBD2, were found in soybean. IBB1 inhibited both trypsin and chymotrypsin while IBBD2 was trypsin-specific. The median inhibitory concentration values of IBB1 and IBBD2 on HT29 colon cancer cell growth were not significantly different (39.9+/-2.3 and 48.3+/-3.5 M, respectively). The distribution pattern of HT29 colon cancer cells was affected by BBI: cells remained in the G0-G1 phase of the cell cycle [20].

\section{Kunitz trypsininhibitor}

Duranti et al described a method for the extraction and purification of Kunitz trypsin inhibitor from soybean seeds. The first step involved heat treatment of whole soybean seeds in water at $60{ }^{\circ} \mathrm{C}$ for $90 \mathrm{~min}$. It was found that $8.4 \%$ of total trypsin inhibitory activity of the seeds was secreted during heat treatment. The aqueous medium was applied on an affinity chromatography column with immobilized trypsin. The method is readily scalable to pilot plant or industrial preparations [21].

\section{Hemagglutinin}

Soybean agglutinin (SBA) is a specific $\mathrm{N}$-acetylgalactosamine-binding lectin that can agglutinate a number of cell types. SBA has potential for utilization as an affinity tag for high-quality purification of tagged proteins, isolation of fetal cells from maternal blood for genetic screening, screening and treatment of breast cancer, and use as a carrier system for oral drug delivery. Tremblay et al employed transient and stable expression systems in potato and Nicotiana benthamiana, respectively, for the production of recombinant SBA, with the trans- 
genic protein accumulated to $0.3 \%$ and $4 \%$ of total soluble protein in potato tubers and $\mathrm{Nic}^{-}$ otiana benthamiana leaves, respectively. Both rSBAs were able to resist degradation in simulated gastric and intestinal fluids. High yield and purity of rSBA can be obtained by affinity column chromatography using $\mathrm{N}$-acetylgalactosamine as a specific ligand [22].

\section{Glyceollins}

Glyceollins produced from daidzein in soybeans cultured with fungi exert antifungal and cancer preventive actions [23]. Isoflavones and metabolites serve as a mixed agonist/antagonist for estrogen. Glyceollins suppress some cancer cells via anti-estrogenic activity. Estrogenic effects of glyceollins have been demonstrated using E-screen assay and pS2 expression. Glyceollins exhibited higher affinity for estrogen receptor beta than estrogen receptor alpha. After Aspergillus sojae infection glyceollins were more efficiently produced de novo in minced soybean than in half-sliced soybean. Hence glyceollins may be useful for preventing or alleviating postmenopausal complications due to potent estrogenic activity, and their production could be varied depending upon processing prior to fungal inoculation [23].

\section{EAR-motif-containing gene GmERF4}

The ERF-associated amphiphilic repression (EAR) motif is vital for transcriptional repression. The soybean protein GmERF4 contains one AP2/ERF domain, two putative nuclear localization signal regions and one EAR motif. It is preferentially localized in the nuclei of onion epidermis cells and bound specifically to the GCC box and DRE/CRT element in vitro. Its expression was inducible by soybean mosaic virus, salt, cold, drought, ethylene, jasmonic acid, and salicylic acid, and inhibited by abscisic acid. Constitutive expression of GmERF4 in transgenic tobacco plants enhanced tolerance to salt and drought stresses compared with wild-type plants, but did not elicit detectable resistance against bacterial infection [24].

\section{Isoflavones}

Contradictory reports are available on the influence of source of dietary protein and soy isoflavones on blood pressure. Therefore, Gilani et al. conducted a study to examine whether the source of dietary protein (casein vs. soybean protein, washed by alcohol to eliminate most isoflavones), dietary extracted soybean isoflavones and anthocyanins modulate the lifespan of Stroke-prone Spontaneously Hypertensive rats. The survival times and survival rates of animals fed casein and soybean protein diets were not statistically different. However, there was a significant effect of isoflavone or anthocyanins supplementation on survival times and survival rates. Death occurred significantly earlier in the isoflavones- or anthocyanins-supplemented groups [25]. 


\section{Soybean resistant protein}

The effect of soybean resistant protein on cholesterol levels in serum and the liver and fecal steroid excretion was examined. The protein downregulated hepatic cholesterol, probably because of elevated excretion of cholesterol and bile acids. The serum cholesterol level was not different as between resistant protein and other soy-derived proteins [26].

\section{Isoflavone-deprived soy peptide}

NF-gammaB mediates processes of carcinogenesis related to deregulation of the normal control of proliferation, angiogenesis, and metastasis. NF-gammaB suppression is associated with cancer chemoprevention. Heat shock protein 90 is important to NF-gammaB activation and stabilizes key proteins implicated in cell cycle control and apoptosis signaling. Administration of isoflavone-deprived soy peptide (3.3 g/rat/day) in the diet reduced the incidence of 7,12-dimethylbenz[alpha]anthracene (DMBA)-induced rat mammary ductal carcinomas, the number of tumors, and prolonged the latency period of tumor development compared to control diet animals. Isoflavone-deprived soy peptide downregulates the expression of heat shock protein 90 , hence thwarting the signaling pathway that brings about NF-gammaB activation.It upregulates the expression of p21, p53, and caspase-3 proteins; and downregulates the expression of VEGF. In keeping with in vivo, treatment with the soy peptide inhibited growth and induced apoptosis in human breast MCF-7 tumor cells. [27].

\section{Neutral PR-5protein}

A gene designated as Glycine max osmotin-like protein, b isoform (GmOLPb, accession no. AB370233) encodes a putative protein with striking resemblance (89\% identity) to chickpea PR-5b. In contrast to the two acidic isoforms of soybean PR-5 protein (GmOLPa and P21), $\mathrm{GmOLPb}$ possesses a C-terminal extension for possible vacuolar targeting and after maturation displays a calculated molecular mass of $21.9 \mathrm{kDa}$ and a $\mathrm{pI}$ of 6.0 . Under conditions of high-salt stress, GmOLPb was highly induced in the leaves 18-72h after onset of the stress. Gene expression of P21e (a homolog of P21) was transiently induced by high-salt stress, but this occurred prior to the gene expression of GmOLPa and GmOLPb. Differential expression also was noted in studies employing methyl jasmonate and salicylic acid. These results suggested that each soybean PR-5 might have a unique function in the defensive system to protect the soybean plant from stress imposed by high salt, especially in the leaves [28].

\section{New defense gene}

The SbPRP gene putatively encodes a bimodular protein with 126 amino acids similar to developmentally regulated proteins in other plants. It has a distinct proline-rich domain (17 
amino acids) and a long hydrophobically cysteine-rich domain (84 amino acids). Its steadystate mRNA level accumulated differentially in response to salicylic acid, and to the inoculation of soybean mosaic virus Sa strain. It responded to drought treatment and salt stress. It appears that SbPRP plays a defense role in soybean [29].

\section{SBTX, a new toxic protein distinct from soyatoxin}

SBTX is a $44-\mathrm{kDa}$ basic glycoprotein composed of a $27-\mathrm{kDa}$ polypeptide chain and a $17-$ $\mathrm{kDa}$ polypeptide chain linked by a disulfide bond. The $\mathrm{N}$-terminal sequences of the 44 and $27 \mathrm{kDa}$ chains were identical. The secondary structure content was $35 \%$ alpha-helix, 13\% beta-strand and beta-sheet, $27 \%$ beta-turn, $25 \%$ unordered, and $1 \%$ aromatic residues. SBTX lacked protease-inhibitory and hemagglutinating activities, but was immunologically related to other toxic proteins, such as soyatoxin and canatoxin, and cross-reacted weekly with soybean trypsin inhibitor and agglutinin. It inhibited the growth of Cercospora sojina, a fungus causing frogeye leaf spot in soybeans at a concentration much lower than the lethal dose to mice. Thus it may be useful for the development of transgenic plants with augmented resistance to pathogens [30].

\section{Ferritin}

Soybean seed ferritin contains a great deal of bioavailable iron and is important for human iron supplementation and prevention of anemia caused by iron deficiency. Dong et al [31] employed a rapid and simple Escherichia coli expression system for producing the soybean seed ferritin complex. The two subunits, H-2 and H-1, were encoded in a single plasmid, and optimal expression was accomplished by coexpressing in addition a team of molecular chaperones, trigger factor and GroEL-GroES. The His-tagged ferritin complex was purified by $\mathrm{Ni}^{2+}$ affinity chromatography. An intact ferritin complex was obtained following His-tagged enterokinase digestion [31].

\section{Peroxisomal proteins}

Peroxisomal proteins comprise enzymes for metabolite transport, stress response, fatty acid beta-oxidation, the glyoxylate cycle, and photorespiratory glycolate metabolism, an enoylCoA hydratase/isomerase family protein, a short-chain dehydrogenase/reductase family protein, 3-hydroxyacyl-CoA dehydrogenase-like protein, and a voltage-dependent anion-selective channel protein [32]. 


\section{Calmodulin}

Calmodulin ( $\mathrm{CaM})$ plays a role in defense responses in plants. In soybean, induction of transcription of calmodulin isoform 4 (GmCaM4) occurred within half an hour following pathogen stimulation. . Park et al utilized the yeast one-hybrid system to isolate two cDNA clones encoding proteins (GmZF-HD1 and GmZF-HD2) which bind to a 30-nt A/T-rich sequence in the GmCaM4 promoter, a region with two repeats of a conserved homeodomain binding site, ATTA. The two proteins are members of the zinc finger homeodomain (ZF-HD) transcription factor family. A homeodomain motif, but not the two zinc finger domains, is capable of binding to the 30-nt GmCaM4 promoter sequence. The interaction between GmZFHD1 and two homeodomain binding site repeats is subject to regulation by pathogen stimulation. GmZF-HD1 can activate the expression of GmCaM4 through interaction with the two repeats. Thus GmZF-HD1 and GmZF-HD-2 proteins are ZF-HD transcription factors that activate GmCaM4 gene expression upon encounter with a pathogen [33].

\section{Soybean disease resistance protein RHG1-LRR domain}

RHG1 encoded by rhg1 was a soybean transmembrane receptor-like kinase (EC 2.7.11.1) with an extracellular leucine-rich repeat (LRR) domain. The LRR of RHG1 was believed to be involved in elicitor recognition and interaction with other plant proteins. Afzal and Lightfoot expressed the LRR domain in Escherichia coli (RHG1-LRR) and produce refolded protein [34].

\section{ABC-transporter}

A new ATP-binding cassette (ABC) transporter was identified as a salicylic acid-induced gene from soybean in a subtractive suppression hybridization approach. The encoded 1447amino acid protein has two similar repeat units typical of full-size ABC transporters and a close relationship to plant pleiotropic drug resistance (PDR)-type transporters. GmPDR12 responds quickly to salicylic acid, functional analogues of salicylic acid and methyl jasmonate. Salicylic acid is required for the hypersensitive reaction in soybean cell suspension cultures inoculated with Pseudomonas syringae pv. glycinea [35].

\section{Beta-glucan-binding protein}

Soybean beta-glucan-binding protein (GBP) binds a microbial cell wall elicitor, triggering the activation of defense responses. It hydrolyzes beta-1,3-glucans present in the cell walls of potential pathogens [36]. 


\section{Lunasin}

Lunasin, a chemopreventive soybean peptide, suppresses transformation of mammalian cells induced by chemical carcinogens and inhibits skin carcinogenesis in mice. All lunasin fractions partially purified by anion exchange and immunoaffinity column chromatography inhibit colony formation induced by the ras-oncogene and inhibit core H3-histone acetylation. The peptide is found in different soybean varieties and commercially available soy proteins by Western blot analysis [37].

\section{Pti1 homologue}

A full-length Pti1-like gene GmPti1, encoding a protein of 366 amino acids with a Ser/Thr/Tyr kinase domain, was identified from soybean in an EST sequencing project by its homology to tomato Pti1. GmPti1 expression was inducible by wounding and salicylic acid. GmPti1 protein was expressed in E. coli as an MBP fusion, purified by amylase resin and examined for its autophosphorylation ability. GmPti1 exhibited kinase activity in the presence of $\mathrm{Mn}^{2+}$ ions [38].

\section{Glysojanin}

A monomeric 25-kDa antifungal protein designated as glysojanin, with an N-terminal sequence resembling a segment of chitin synthase, was isolated from the seeds of the black soybean Glycine soja. The protein demonstrated potent antifungal activity against the fungi Fusarium oxysporum and Mycosphaerella arachidicola. It inhibited [methyl- ${ }^{3} \mathrm{H}$ ] thymidine incorporation by mouse spleen cells with an $\mathrm{IC}_{50}$ of $175 \mathrm{M}$, translation in the rabbit reticulocyte lysate with an $\mathrm{IC}_{50}$ of $20 \mathrm{M}$, and HIV-1 reverse transcriptase with an $\mathrm{IC}_{50}$ of $47 \mathrm{M}$ [39].

\section{Syringolide-induced/ HCD associated proteins}

Syringolide elicitors produced by bacteria expressing Pseudomonas syringae pv. glycinea avirulence gene $\mathrm{D}(\mathrm{avrD})$ induce hypersensitive cell death (HCD) only in soybean (Glycine max [L.] Merr.) plants carrying the Rpg4 disease resistance gene. Employing a differential display method, we isolated 13 gene fragments induced in cultured cells of a soybean cultivar Harosoy (Rpg4) treated with syringolides. Several genes for isolated fragments were induced by syringolides in an rpg4 cultivar Acme as well as in Harosoy; however, the genes for seven fragments designated as SIH (for syringolide-induced/HCD associated) were induced exclusively or strongly in Harosoy. cDNA clones for SIH genes were obtained from a cDNA library of Harosoy treated with syringolide. Several sequences are homologous to proteins associated with plant defense responses. The SIH genes did not respond to a non-specific beta-glucan elicitor, which induces phytoalexin accumulation but not HCD, suggesting that the induction of the SIH genes is specif- 
ic for the syringolide-Harosoy interaction. $\mathrm{HCD}$ and the induction of $\mathrm{SIH}$ genes by syringolides were independent of $\mathrm{H}_{2} \mathrm{O}_{2}$. On the other hand, $\mathrm{Ca}^{2+}$ was required for $\mathrm{HCD}$ and the induction of some SIH genes. These results suggest that the induction of SIH genes by syringolides could be activated through the syringolide-specific signaling pathway and the SIH gene products may play an important role(s) in the processes of HCD induced by syringolides [40].

\section{Anticarcinogenicdaidzein-rich fraction}

Partial purification of the methanol extract of soybean powder, by employing solvent fractionation and silica gel chromatography, yielded an active fraction rich in daidzein with an active component(s) that enhanced HL-60 cell differentiation. The fraction appeared to exert cytotoxic activity via an apoptotic pathway as evidenced by DNA fragmentation and caspase-3 induction. It also upregulated TGF-beta2 expression, but did not affect the expression of other members of the TGF-beta family of cytokines and their receptors, or on the expression of the vascular endothelial growth factor gene [41].

\section{Phenylalanine ammonia-lyase and tyrosineammonia-lyase}

Key enzymes of the phenylpropanoid pathway including phenylalanine ammonia-lyase and tyrosine ammonia-lyase are induced in response to biotic (such as chitin from fungal cell walls) and abiotic cues. The elevation of enzyme activity enzymes following application of chitin and chitosan to soybean leaf tissues was dependent on the chain length of the oligomers and time post-treatment. Treatment with chitin hexamer and chitosan pentamer produced the maximal activities at $36 \mathrm{~h}$. Total phenolic content of soybean leaves rose, indicating a positive correlation between enzyme activity and total phenolic content [42].

\section{Defense-related enzymes}

A new class of bacteriocin (class IId) stimulates plant growth in a way analogous to Nod factors which have been shown to provoke aspects of plant disease resistance. Cut stems of soybean seedlings at the first trifoliate stage were exposed to the bacteriocin solutions Phenylalanine ammonia lyase (PAL) activity, superoxide dismutase (SOD) activity, and one APX isozyme (28kDa isoform) level in bacteriocins thuricin 17 (T17)-treated leaves peaked at $72 \mathrm{~h}$ after treatment. At $72 \mathrm{~h}$ post-treatment, compared with the control, guaiacol peroxidase (POD) activity in leaves exposed to T17 and bacteriocin bacthuricin F4 (BF4) rose by 72.7 and $91.3 \%$, respectively; ascorbate peroxidase (APX) activity increased by 52.3 and $49.6 \%$; and SOD activity was elevated by 70.5 and $60.2 \%$, respectively. The $33-\mathrm{kDa}$ polyphenol oxidase isozyme was induced strongly by both bacteriocins. Thus class IId bacteriocins can act as an inducer of plant disease defense-related enzymes and may employ mechanisms similar to Nod factors [43]. 


\section{Cysteine proteinase}

Two cDNAs, were isolated from the cotyledons of growing soybean seedlings by cDNA representational difference analysis (cDNA RDA) and rapid amplification of cDNA ends (RACE). Both CysP1 and CysP2 encode a cysteine proteinase (CPR) with a C-terminal KDEL motif. CysP1 and CysP2 were expressed from 6 days to 13 or 14 days after germination in the cotyledons of growing seedlings and in the root, flower and pod of soybean plants [44].

Two types of cysteine proteases, low-specificity enzymes from the papain family and Asnspecific enzymes from the legumin family, are endopeptidases that play a role in the degradation of seed storage proteins during early growth of seedlings. The action of the enzymes (CPPh1 and LLP, respectively) from the common bean (Phaseolus vulgaris L.) on the common bean storage protein phaseolin, and on the homologous soybean storage protein beta-conglycinin, has been examined. The two most active proteinases detected in common bean seedlings individually cannot bring about extensive degradation of phaseolin. However, the successive action of LLP and CPPh1 leads to extensive hydrolysis of phaseolin. CPPh1 accomplished extensive hydrolysis of beta-conglycinin [45].

\section{Isoflavone synthase}

Isoflavonoids are secondary metabolites important in nodulation and defense responses. They have a common occurrence in leguminous plants. Isoflavone synthase (IFS) catalyzes the key entry point step of isoflavone biosynthesis from the general phenylpropanoid pathway. IFS transcripts were detected in seeds and roots. The transcript levels of the isoforms IFS1 and IFS2 are altered in response to Bradyrhizobium japonicum or salicylic acid. The expression pattern of IFS1 in soybean is indicative of the roles of isoflavonoids in defense against pathogens and signal molecules to symbiotic bacteria [46].

\section{UDP-glucose:Flavonoid 3-O-glucosyltransferase}

The seed coats of black soybean accumulate red (cyanidin-based), orange (pelargonidinbased) blue (delphinidin-based), purple (petunidin-based), and anthocyanins almost exclusively as 3-O-glucosidesThe full-length cDNA encoding UDP-glucose:flavonoid 3-Oglucosyltransferase (UGT78K1), the enzyme which catalyzes the last step in anthocyanin biosynthesis, was isolated from black soybean seed coat using rapid amplification of cDNA ends (RACE). The recombinant enzyme glucosylated only anthocyanidins and flavonols with 3-OH regiospecificity. Galactose could also be transferred, albeit with relatively low activity, to the 3-position of cyanidin or delphinidin in vitro. The results are consistent with the presence of mainly 3-O-glucosylated and minor amounts of 3-O-galactosylated anthocyanins in the black soybean seed coat. The recombinant enzyme exhibited pronounced substrate inhibition by cyanidin at $100 \mathrm{M}$ acceptor concentration. The accumulation of 
anthocyanins and flavonols was reinstated by transfer of UGT78K1 into the Arabidopsis TDNA mutant (ugt78d2) lacking in anthocyanidin and flavonol 3-O-glucosyltransferase activity, signifying the role of the enzyme as a flavonoid 3-O-glucosyltransferase. Genomic and phylogenetic analyses suggest the presence of three additional soybean sequences with remarkable homology to UGT78K1. RT-PCR confirmed the co-expression of one of these genes (Glyma08g07130) with UGT78K1 in the black soybean seed coat, suggesting possible functional redundancies in anthocyanin biosynthesis in this tissue [47].

\section{Beta-glucosidase}

A novel 75-kDa beta-glucosidase with strict specificity toward glucosyl isoflavones but not malonylglucosidic conjugates of soybean isoflavones, was isolated from soybean. Its N-terminal amino acid sequence EYLKYKDPKA closely resembled those of maize and wheat glycosidases. Its optimal temperature and $\mathrm{pH}$ were 45 degrees $\mathrm{C}$ and 4.5 , respectively. It was completely inhibited by $1 \mathrm{mM} \mathrm{Hg}^{2+}$ or $10 \mathrm{mM} \mathrm{Al}^{3+}$ ion, and glucose and mannose also affected the activity [48].

\section{Isoflavone conjugate-hydrolyzing beta-glucosidase}

Soybeans excrete from the roots isoflavones, which are involved in plant-microbe interactions such as symbiosis and as a defense against infections. The release of free isoflavones from their conjugates, the latent forms, is catalyzed by an isoflavone conjugatehydrolyzing beta-glucosidase. The purified enzyme, isoflavone conjugate-hydrolyzing beta-glucosidase from (GmICHG), is a homodimeric 116-Da glycoprotein capable of directly hydrolyzing genistein 7-O-(6 "-O-malonyl-beta-d-glucoside) to yield free genistein. GmICHG cDNA is highly expressed in the seedling roots but only very weakly in cotyledons and hypocotyls. The enzyme is exclusively localized in the cell wall and intercellular space of seedling roots, especially in the cell wall of root hairs. GmICHG is a member of glycoside hydrolase family 1 [49].

\section{Isocitratelyase}

A four-stage purification procedure comprising ammonium sulfate precipitation and ion exchange chromatography on DEAE cellulose has been elaborated for isolation of isocitrate lyase (EC 4.1.3.1) isoforms from soybean cotyledons, the isoform that migrated quickly in PAAG had a much lower affinity to isocitrate $\left(\mathrm{K}_{\mathrm{M}}-50 \mathrm{M}\right)$ than the slowly migrating form $\left(\mathrm{K}_{\mathrm{M}}-16 \mathrm{M}\right)$. The conservation of activity of the isoforms obtained depends on the presence of divalent cations $\left(\mathrm{Mn}^{2+}\right.$ and $\left.\mathrm{Mg}^{2+}\right)$ in the medium. It is suggested to use the isoforms of isocitrate lyase isolated from soybeans for the development of biosensors for biochemical and kinetic assays [50]. 


\section{Vestitonereductase and chalconereductase}

The complete mRNA sequences of two soybean genes-vestitone reductase and chalcone reductase, were amplified using the rapid amplification of cDNA ends methods. Soybean vestitone reductase gene encodes a 327 amino-acid protein with pronounced resemblance to Medicago sativa vestitone reductase. The soybean chalcone reductase gene encodes a 314 amino-acid protein highly homologous to the kudzu vine and medicago sativa chalcone reductases. The two genes were differentially expressed in soybean embryos and endosperm, flowers, leaves, stems, and roots [51].

\section{Genes related to 2-oxoglutarate-dependentdioxygenases}

A screening for genes involved in root nodule senescence has resulted in the isolation of the senescence-associated nodulin 1 (SAN1) multigene family from soybean. The SAN1-encoded proteins display sequence resemblance and highly conserved motifs with plant 2-oxoglutarate-dependent dioxygenases (2-ODDs). SAN1A is downregulated whereas SAN1B is upregulated during senescence induced by treatment with fixed nitrogen or darkness. The expression of the SAN1genes is not found only in nodules, signifying a more general role in plant metabolism [52].

\section{5'-adenylylsulfate reductase}

Soybean seeds contain only low levels of sulfur-containing amino acids. Although expressed in various tissues throughout the plant, there is an abundant expression of the APS reductase gene and activity of the encoded protein in the early developmental stages of soybean seed, which decreases as the seed matures. Sulfur and phosphorus deprivation and coldtreatment elevate the expression level, while nitrogen starvation reduces APS reductase mRNA transcript and protein levels. This study allows an insight into the sulfur assimilation pathway [53].

\section{Soybean ATP sulfurylase}

Analysis of the ATP sulfurylase ATPS clone isolated from a soybean seedling cDNA library revealed an open-reading frame, encoding a 52-kDa polypeptide with an $\mathrm{N}$ terminal chloroplast/plastid transit peptide. ATP sulfurylase mRNA was present with the highest abundance in root tissue. mRNA accumulated and the specific activity of ATP sulfurylase in root tissue was enhanced by cold treatment. The transcript levels and specific activity of the enzyme dropped during the later stages of seed development. Augmenting the expression levels of this key enzyme during soybean seed de- 
velopment could increase the availability of sulfur amino acids and elevate the nutritional value of the crop [54].

\section{Polysaccharides}

Soluble soybean polysaccharide (SSPS) was fractionated into two sub-fractions, a highmolecular-weight fraction (HMF) and a low-molecular-weight fraction (LMF) by the ethanol-extraction method. The major constituent of HMF was a large polysaccharide with covalently-attached peptides, probably corresponding to the intact SSPS molecule. LMF was composed of free peptides and saccharides of small size, which might have occurred as by-products during the process of SSPS production. HMF exhibited high ability to emulsify oil droplets and stabilize alpha-casein dispersions in an acidic $\mathrm{pH}$ region. LMF showed lower activity in this regard although but it had higher potency in preventing the oxidation of emulsified lipids. The data indicate that HMF and LMF possess dissimilar structural and functional characteristics, and that the combination of the two sub-fractions displays the multiple functions of commercial SSPS [55].

\section{Conclusion}

The foregoing account has shown a constellation of bioactive constituents in soybean. They include enzymes that catalyze crucial steps in metabolic pathways, and also nonenzymatic proteins with important activities such as defense. Storage proteins in soybean like glycinin and conglycinin exhibit health promoting activities. Other proteins and peptides have blood pressure lowering and anticarcinogenic activities. It is anticipated that more components with potentially exploitable activities will be discovered and more applications of these soybean components to the benefit of mankind will be found.

\section{Author details}

Tzi Bun Ng*, Randy Chi Fai Cheung and Jack Ho Wong

*Address all correspondence to: b021770@mailserv.cuhk.edu.hk, jack1993@yahoo.com

School of Biomedical Sciences, Faculty of Medicine, The Chinese University of Hong Kong, Hong Kong, China 


\section{References}

[1] Natarajan SS, Xu C, Bae H, Caperna TJ, Garrett WM. Characterization of storage proteins in wild (Glycine soja) and cultivated(Glycine max) soybean seeds using proteomic analysis. J Agric Food Chem. 2006;54(8)3114-20.

[2] Krishnan HB, Oehrle NW, Natarajan SS.A rapid and simple procedure for the depletion of abundant storage proteins from legume seeds to advance proteome analysis: a case study using Glycine max. Proteomics 2009;9(11)3174-88.

[3] Ferreira ES, Silva MA, Demonte A, Neves VA. $\beta$-conglycinin combined with fenofibrate or rosuvastatin have exerted distinct hypocholesterolemic effects in rats. Lipids Health Dis. 2012;1111.

[4] Hou DH, Chang SK. Structural characteristics of purified glycinin from soybeans stored undervarious conditions. J Agric Food Chem. 2004;52(12)3792-800.

[5] Fassini PG, Noda RW, Ferreira ES, Silva MA, Neves VA, Demonte A.Soybean glycinin improves HDL-C and suppresses the effects of rosuvastatin onhypercholesterolemic rats. Lipids Health Dis. 2011;10:165.

[6] Sitohy MZ, Mahgoub SA, Osman AO. In vitro and in situ antimicrobial action and mechanism of glycinin and its basicsubunit. Int J Food Microbiol. 2012;15419-29.

[7] Duranti M, Lovati MR, Dani V, Barbiroli A, Scarafoni A, Castiglioni S, Ponzone C,Morazzoni P.The alpha' subunit from soybean 7S globulin lowers plasma lipids and upregulates liver beta-VLDL receptors in rats fed a hypercholesterolemic diet. J Nutr. 2004;134(6)1334-9.

[8] Yoshizawa T, Hashimoto H, Shimizu T, Yamabe M, Shichijo N, Hanada K, Hirano H,Sato M.Purification, crystallization and X-ray diffraction study of basic 7S globulinfrom soybean. ActaCrystallogr Sect F StructBiolCrystCommun. 2011;6787-9.

[9] Rouquié D, Capt A, Eby WH, Sekar V, Hérouet-Guicheney C. Investigation of endogenous soybean food allergens by using a 2-dimensional gelelectrophoresis approach. RegulToxicolPharmacol. 2010;3SupplS47-53.

[10] Wilson S, Martinez-Villaluenga C, De Mejia EG. Purification, thermal stability, and antigenicity of the immunodominant soybeanallergen P34 in soy cultivars, ingredients, and products J Food Sci. 2008;73(6)T106-14.

[11] Morita H, Kaneko H, Ohnishi H, Kato Z, Kubota K, Yamamoto T, Matsui E, TeramotoT, Fukao T, Kasahara K, Kondo N. Structural property of soybean protein P34 and specific IgE response torecombinant P34 in patients with soybean allergy. Int J Mol Med. 2012;29153-8.

[12] Yamaguchi Y, Barona G, Ryan CA, Pearce G.GmPep914, an eight-amino acid peptide isolated from soybean leaves, activatesdefense-related genes. Plant Physiol. 2011;156(2)32-42. 
[13] Koo KB, Suh HJ, Ra KS, Choi JW. Protective effect of cyclo(his-pro) on streptozotocin-induced cytotoxicity andapoptosis in vitro. J MicrobiolBiotechnol. 2011;21(2)218-27.

[14] Egusa S, Otani H. Characterization of a cellular immunostimulating peptide from a soybean proteinfraction digested with peptidase R. J NutrSciVitaminol (Tokyo). 2009;55(5)428-33.

[15] Torre-Villalvazo I, Gonzalez F, Aguilar-Salinas CA, Tovar AR, Torres N. Dietary soy protein reduces cardiac lipid accumulation and the ceramideconcentration in highfat diet-fed rats and ob/ob mice. J Nutr. 2009;139(12)2237-43.

[16] Cha M, Park JR. Production and characterization of a soy protein-derived angiotensin I-convertingenzyme inhibitory hydrolysate. J Med Food. 2005;8(3)305-10.

[17] Kuba M, Tanaka K, Tawata S, Takeda Y, Yasuda M.Angiotensin I-converting enzyme inhibitory peptides isolated from tofuyofermented soybean food. BiosciBiotechnolBiochem. 2003;67(6)1278-83.

[18] Mallikarjun Gouda KG, Gowda LR, Rao AG, Prakash V. Angiotensin I-converting enzyme inhibitory peptide derived from glycinin, the 11Sglobulin of soybean (Glycine max). J Agric Food Chem. 2006;54(13)4568-73.

[19] Anta L, Luisa Marina M, García MC.Simultaneous and rapid determination of the anticarcinogenic proteins Bowman-Birkinhibitor and lectin in soybean crops by perfusion RP-HPLC. J Chromatogr A. 2010;1217(45)7138-43.

[20] Clemente A, Moreno FJ, Marín-ManzanoMdel C, Jiménez E, Domoney C. The cytotoxic effect of Bowman-Birkisoinhibitors, IBB1 and IBBD2, from soybean(Glycine max) on HT29 human colorectal cancer cells is related to their intrinsicability to inhibit serine proteases.Mol NutrFood Res. 2010;54(3):396-405.

[21] Duranti M, Barbiroli A, Scarafoni A, Tedeschi G, Morazzoni P. One-step purification of Kunitz soybean trypsin inhibitor. Protein ExprPurif. 2003;30(2)167-70.

[22] Tremblay R, Feng M, Menassa R, Huner NP, Jevnikar AM, Ma S. High-yield expression of recombinant soybean agglutinin in plants using transientand stable systems. Transgenic Res. 2011;20(2)345-56.

[23] Kim HJ, Suh HJ, Kim JH, Kang SC, Park S, Lee CH, Kim JS. Estrogenic activity of glyceollins isolated from soybean elicited withAspergillussojae. J Med Food. 2010;13(2)382-90.

[24] Zhang G, Chen M, Chen X, Xu Z, Li L, Guo J, Ma Y. Isolation and characterization of a novel EAR-motif-containing gene GmERF4 fromsoybean (Glycine max L.). MolBiol Rep. 2010;37(2)809-18.

[25] Gilani GS, NimalRatnayke WM, Mueller R, Mazza G. Effects of source of protein and supplementary extracted isoflavones andanthocyanins on longevity of Stroke-prone Spontaneously Hypertensive (SHRSP)rats. J Toxicol Sci. 2009;34(3)335-41. 
[26] Yamatani K, Saeki T, Iwami K, Suzuka T, Kanamoto R.Soybean resistant protein elevates fecal excretion of cholesterol and bile acids and decreases hepatic cholesterol content in comparison with soybean proteinisolate. BiosciBiotechnolBiochem. 2009;73(4)921-2.

[27] Park K, Choi K, Kim H, Kim K, Lee MH, Lee JH, Kim Rim JC.Isoflavone-deprived soy peptide suppresses mammary tumorigenesis by inducingapoptosis. ExpMol Med. 2009;41(6)371-81.

[28] Tachi H, Fukuda-Yamada K, Kojima T, Shiraiwa M, Takahara H. Molecular characterization of a novel soybean gene encoding a neutral PR-5protein induced by highsalt stress. Plant PhysiolBiochem. 2009;47(1)73-9.

[29] He C, Wu X, Dongfang Y, Du B, Zhang J, Chen S. Isolation and characterization of a new defense gene from soybean. Sci China C Life Sci. 2001;44(4)409-20.

[30] Vasconcelos IM, Morais JK, Siebra EA, Carlini CR, Sousa DO, Beltramini LM, MeloVM, Oliveira JT. SBTX, a new toxic protein distinct from soyatoxin and other toxic soybean[Glycine max] proteins, and its inhibitory effect on Cercosporasojina growth. Toxicon. 2008;51(6)952-63.

[31] Dong X, Tang B, Li J, Xu Q, Fang S, Hua Z. Expression and purification of intact and functional soybean (Glycine max) seedferritin complex in Escherichia coli. J MicrobiolBiotechnol. 2008;18(2)299-307.

[32] Arai $Y$, Hayashi M, Nishimura M. Proteomic analysis of highly purified peroxisomes from etiolated soybeancotyledons. Plant Cell Physiol. 2008;49(4)526-39.

[33] Park HC, Kim ML, Lee SM, Bahk JD, Yun DJ, Lim CO, Hong JC, Lee SY, Cho MJ, Chung WS.Pathogen-induced binding of the soybean zinc finger homeodomain proteins GmZF-HD1and GmZF-HD2 to two repeats of ATTA homeodomain binding site in the calmodulinisoform 4 (GmCaM4) promoter. Nucleic Acids Res. 2007;35(11)3612-23.

[34] Afzal AJ, Lightfoot DA.Soybean disease resistance protein RHG1-LRR domain expressed, purified andrefolded from Escherichia coli inclusion bodies: preparation for a functionalanalysis. Protein ExprPurif. 2007;53(2)346-55.

[35] Eichhorn H, Klinghammer M, Becht P, Tenhaken R. Isolation of a novel ABC-transporter gene from soybean induced by salicylic acid. J Exp Bot. 2006;57(10)2193-201.

[36] Fliegmann J, Montel E, Djulić A, Cottaz S, Driguez H, Ebel J. Catalytic properties of the bifunctional soybean beta-glucan-binding protein, amember of family 81 glycoside hydrolases. FEBS Lett. 2005;579(29)6647-52.

[37] Jeong HJ, Park JH, Lam Y, de Lumen BO. Characterization of lunasin isolated from soybean. J Agric Food Chem. 2003;51(27)7901-6.

[38] Tian AG, Luo GZ, Wang YJ, Zhang JS, Gai JY, Chen SY. Isolation and characterization of a Pti1 homologue from soybean. J Exp Bot. 2004;55(396)535-7. 
[39] Ngai PH, Ng TB.Purification of glysojanin, an antifungal protein, from the black soybean Glycinesoja. Biochem Cell Biol. 2003;81(6)387-94.

[40] Hagihara T, Hashi M, Takeuchi Y, Yamaoka N. Cloning of soybean genes induced during hypersensitive cell death caused bysyringolide elicitor. Planta. 2004;218(4)606-14.

[41] Lee JS, Son KH, Sung MK, Kim YK, Yu R, Kim JS. Anticarcinogenic properties of a daidzein-rich fraction isolated from soybean. J Med Food. 2003;6(3)175-81.

[42] Khan W, Prithiviraj B, Smith DL.Chitosan and chitin oligomers increase phenylalanine ammonia-lyase and tyrosineammonia-lyase activities in soybean leaves. J Plant Physiol. 2003;160(8)859-63.

[43] Jung WJ, Mabood F, Souleimanov A, Smith DL.Induction of defense-related enzymes in soybean leaves by class IIdbacteriocins (thuricin 17 and bacthuricin F4) purified from Bacillus strains.Microbiol Res. 2011;167(1)14-9.

[44] Ling JQ, Kojima T, Shiraiwa M, Takahara H. Cloning of two cysteine proteinase genes, CysP1 and CysP2, from soybeancotyledons by cDNA representational difference analysis. BiochimBiophysActa. 2003;1627(2-3)129-39.

[45] Zakharov A, Carchilan M, Stepurina T, Rotari V, Wilson K, Vaintraub I. A comparative study of the role of the major proteinases of germinated commonbean (Phaseolus vulgaris L.) and soybean (Glycine max (L.) Merrill) seeds in the degradation of their storage proteins. J Exp Bot. 2004;55(406)2241-9.

[46] Subramanian S, Hu X, Lu G, Odelland JT, Yu O. The promoters of two isoflavone synthase genes respond differentially tonodulation and defense signals in transgenic soybean roots. Plant Mol Biol. 2004;54(5)623-39.

[47] Kovinich N, Saleem A, Arnason JT, Miki B. Functional characterization of a UDP-glucose:flavonoid 3-O-glucosyltransferasefrom the seed coat of black soybean (Glycine $\max ($ L.) Merr.). Phytochemistry. 2010;71(11-12)1253-63.

[48] Chiou TY, Lin YH, Su NW, Lee MH. Beta-glucosidase isolated from soybean okara shows specificity toward glucosylisoflavones. J Agric Food Chem. 2010;58(15)8872-8.

[49] Suzuki H, Takahashi S, Watanabe R, Fukushima Y, Fujita N, Noguchi A, Yokoyama R, Nishitani K, Nishino T, Nakayama T.An isoflavone conjugate-hydrolyzing betaglucosidase from the roots of soybean(Glycine max) seedlings: purification, gene cloning, phylogenetics, and cellular localization. J Biol Chem. 2006;281(40)30251-9.

[50] Eprintsev AT, Diachenko EV, Lykova TV, Kuen CT, Popov VN. Preparation and properties of isocitratelyase isoforms from the cotyledons ofGlycine max L. PriklBiokhimMikrobiol. 2010;46(1)103-8.

[51] Liu GY. Isolation, sequence identification and tissue expression profile of two novelsoybean (glycine max) genes-vestitonereductase and chalconereductase. MolBiol Rep. 2009;36(7)1991-4. 
[52] Webb CJ, Chan-Weiher C, Johnson DA.Isolation of a novel family of genes related to 2-oxoglutarate-dependentdioxygenases from soybean and analysis of their expression during root nodulesenescence. J Plant Physiol. 2008;165(16)1736-44.

[53] Phartiyal P, Kim WS, Cahoon RE, Jez JM, Krishnan HB. The role of 5'-adenylylsulfate reductase in the sulfur assimilation pathway ofsoybean: molecular cloning, kinetic characterization, and gene expression. Phytochemistry 2008;69(2)356-64.

[54] Phartiyal P, Kim WS, Cahoon RE, Jez JM, Krishnan HB.Soybean ATP sulfurylase, a homodimeric enzyme involved in sulfur assimilation, isabundantly expressed in roots and induced by cold treatment. Arch BiochemBiophys. 2006;450(1)20-9.

[55] Li J, Matsumoto S, Nakamura A, Maeda H, Matsumura Y. Characterization and functional properties of sub-fractions of soluble soybean.BiosciBiotechnolBiochem. 2009;73(12)2568-75. 